\title{
Investigación
}

\section{Límites al poder de reforma en la revisión constitucional del Acto Legislativo 01 de 2017}

Limits to the power of reform in the constitutional review of Legislative Act 01/2017

Asbleidy Inndira Rojas Uribe*

- Recepción:25/02/2020 • Aprobación:22/05/2020 • Publicación: 12/08/2020

Para citar este artículo

Rojas Uribe, A. I. (2020). Límites al poder de reforma en la revisión constitucional del Acto Legislativo 01 de 2017. Dos mil tres mil, 22, e223.

https://doi.org/10.35707/dostresmil/22223
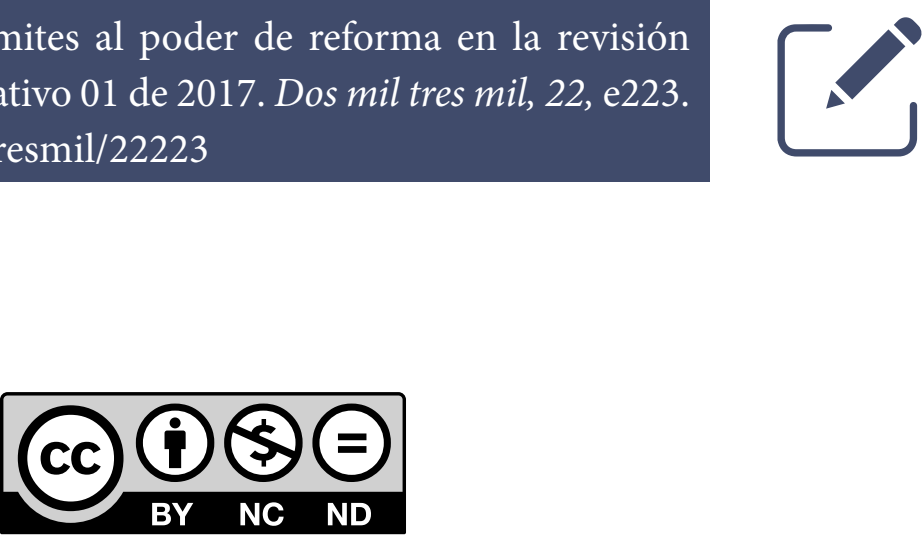

* Estudiante de Maestría en Derecho, Gobierno y Gestión de la Justicia, Universidad de Los Andes, Colombia. ORCID: 0000-00023165-7203. Correo electrónico: indirauribe11@gmail.com. 
Resumen. En este artículo se realiza un análisis desde una visión de la teoría constitucional a los límites al poder de reforma en el marco de la Jurisdicción Especial para la Paz aprobada por el Acto Legislativo 01 de 2017. Para cumplir con el objetivo, se respondieron los siguientes interrogantes: 1) ¿Qué significa que el poder de reforma tenga límites?; 2) ¿cómo llega esa teoría a la Corte Constitucional?; y 3) ¿cómo se analizaron los postulados que componen la Jurisdicción Especial para la Paz por parte de la Corte Constitucional? Resueltos los cuestionamientos, se concluye que es una situación de verdadera excepción constitucional. En esta se evidencia que el juicio de sustitución se encuentra supeditado a una flexibilidad en los escenarios de transición para desarrollar un principio y fin constitucional, como es el de la paz, sin que con ello se reemplacen los aspectos definitorios de la Constitución.

Abstract. In this article, an analysis is made from an outlook of constitutional theory to the limits to the power of reform within the framework of the Special Jurisdiction for Peace approved by Legislative Act 01/2017. To meet the objective, the following questions were answered: 1) What does it mean that the power of reform has limits? 2) How does this theory reach the Constitutional Court? And, 3) How were the postulates that make up the Special Jurisdiction for Peace analyzed by the Constitutional Court? Once the questions are resolved, it is concluded that it is a situation of true constitutional exception. This shows that the substitution trial is subject to flexibility in transition scenarios to develop a constitutional beginning and end, such as that of peace, without replacing defining aspects of the Constitution.

Palabras claves

Jurisdicción Especial para la Paz, límites, reforma constitucional, sistema de control constitucional.

Key words

Special Jurisdiction for Peace, limits, constitutional reform, constitutional control system. 


\section{Introducción}

Ante la búsqueda de una solución negociada definitiva al conflicto armado colombiano, y al reconocer la condición ética del ser humano conforme a la cual una sociedad solo puede subsistir si sus miembros se obligan, entre sí, a respetar los derechos humanos, el 26 de septiembre de 2016, se logró la firma del Acuerdo Final para la Terminación del Conflicto y la Construcción de una Paz Estable y Duradera, entre el Gobierno de Colombia y la extinta guerrilla de las Fuerzas Armadas Revolucionarias de Colombia (en adelante farC).

En virtud de ese acuerdo, se pactó la creación de la Jurisdicción Especial para la Paz (en adelante JEP) como un componente de justicia del Sistema Integral de Verdad, Justicia, Reparación y no Repetición. La JEP tiene la función de administrar justicia transicional y conocer de los delitos cometidos en el marco del conflicto armado efectuados con anterioridad al 1 de diciembre de 2016.

Esa disposición implica una creación normativa para su respectiva implementación dentro del ordenamiento jurídico. En ese sentido, este artículo pretende ir al trasfondo de la discusión sobre reforma y sustitución constitucional, en aras de identificar si la aprobación de la Jurisdicción Especial para la Paz por parte del Congreso de la República mediante el Acto Legislativo 01 de 2017, se encuentra dentro de los límites otorgados a este poder para reformar la Constitución, y que no se trata de una sustitución de la misma. Esto, porque se considera una oportunidad, desde una visión de la teoría constitucional, para estudiar los límites al poder de reforma como componente transversal que enmarca el análisis constitucional dentro del marco jurídico para la paz. Para dar respuesta a tal interrogante, este se estructura en tres partes.

La primera parte estudia la posibilidad de modificación que se inserta en la Constitución Política de 1991. Para ello se desarrolla el concepto de Constitución, la diferenciación entre poder constituyente y poder de reforma, y se establecen los puntos de la discusión entre las posturas procedimentalista y materialista. De ahí que, para resolverlo, se trabaja de la mano de la doctrina de autores como Hans Kelsen (1969) y Carl Schmitt (2001), respectivamente.

La segunda parte da cuenta de la doctrina jurisprudencial que sobre la materia de la reforma constitucional se ha establecido en el país. En ese sentido, se hace alusión a la Sentencia C-551 de 2003, a partir de la cual se introduce el concepto de límites competenciales y se da inicio a la metodología del juicio de sustitución. De manera que con ello quede expuesta la práctica jurisprudencial del máximo órgano constitucional al momento de efectuar su sistema de control constitucional.

La tercera parte comprende el análisis de la Sentencia C-674 de 2017, en la cual la Corte Constitucional realizó la revisión de constitucionalidad del Acto Legislativo 01 de 2017, "por medio del cual se crea un título de disposiciones transitorias de la Constitución para la terminación del conflicto armado y la construcción de una paz estable y duradera y se dictan otras disposiciones", para identificar si la JEP se encuentra dentro de los límites otorgados a este poder para reformar la Constitución, y que no se trata de una sustitución de la misma. 
Para alcanzar el objetivo propuesto, se desarrollan los siguientes interrogantes: 1) ¿Qué significa que el poder de reforma tenga límites? 2) ¿Cómo llega esa teoría a la Corte Constitucional? 3) ¿Cómo se analizaron los postulados que componen la Jurisdicción Especial para la Paz por parte de la Corte Constitucional?, para finalmente arribar a 4) las conclusiones.

\section{1. ¿Qué significa que el poder de reforma tenga límites?}

El poder reformador de la Constitución está instituido por la Carta Fundamental. Constituye una actividad sometida y reglada por la propia Constitución. La reforma constitucional permite afrontar las cambiantes circunstancias históricas y sociales de los pueblos. Ello posibilita su adaptación a los nuevos desafíos y vicisitudes históricas, como puede ser el caso del fin del conflicto armado, pero dentro del marco de la juridicidad y la continuidad de su propia identidad. Esto significa que se deben respetar las formas, procedimientos y contenidos esenciales de la Constitución, por ser un acto del pueblo como poder constituyente.

En Colombia tenemos una Constitución rígida. Esta impide su modificación de manera dúctil e impone procedimientos distintos y más complejos que los procedimientos legislativos ordinarios. La Constitución Política de 1991, a través del Título XIII, regula los procedimientos de reforma (Constitución de Colombia, 1991). Estos se reducen en el texto constitucional a tres: reforma por el Congreso, denominado acto legislativo; reforma por medio de referendo constitucional y reforma mediante la utilización de una asamblea constituyente (Constitución de Colombia, 1991, artículo 374).

Estas tres vías o procedimientos son los únicos establecidos para realizar cambios en el articulado constitucional, como expresión de un poder constituyente constituido. Esto significa que en definitiva se trata de decisiones tomadas por el titular de la soberanía; es decir, el pueblo (Constitución de Colombia, 1991, artículo 3), o bien sea directamente a través de cuerpos elegidos popularmente.

En lo referente a la existencia de límites o condicionamientos para modificar la Carta Política, solo se restringe al tópico del procedimiento (Constitución de Colombia 1991, artículo 241, n. $^{\circ}$ ), para la toma de decisiones, más no sobre el contenido de las mismas. Es por ello que la Constitución Política de 1991 guardó un relativo silencio en cuanto a la existencia de límites materiales al poder de reforma. Se hace alusión a un silencio relativo, porque la redacción del artículo 377 constitucional parece indicar que tal poder cuenta con la facultad de modificar cualquier contenido de la Constitución, al autorizar expresamente la reforma a los derechos fundamentales y sus garantías a los procedimientos de participación popular, o a la estructura del Congreso (Constitución de Colombia, 1991, artículo 377). Permitiendo reformas sobre aspectos de una especial importancia dentro de cualquier texto constitucional.

En esa medida, el poder constituyente instituido se encuentra sometido a la Constitución y sus actos pueden ser objeto de control de constitucionalidad por el órgano jurisdiccional encargado de velar por la defensa de la Constitución. Así lo concibe el artículo 241 constitucional, 
cuando en su numeral $1 .^{\circ}$ solo autoriza a la Corte Constitucional para ejercer un control por vicios de procedimiento en la formación del acto reformatorio de la Constitución.

Al respecto, Zagrebelsky (2000) indica como el poder de revisión constitucional no es el poder constituyente, sino un poder constituido, aunque se trate "del poder dotado de la máxima eficacia jurídica entre todos los previstos en el ordenamiento actual” (p. 73), el cual, como poder constituido, tiene límites. En tal caso, se convertiría en un poder constituyente originario que debiera recabar su legitimación en la voluntad del cuerpo político de la sociedad.

En cuanto a su propósito, Humberto Nogueira señala que:

Un poder constituyente instituido limitado tiene como finalidad evitar la alteración sustantiva de la idea de derecho y principios estructurales básicos contenidos en la Constitución, sin intervención directa del cuerpo político de la sociedad, único legitimado para modificar la idea de derecho contenida en la Carta Fundamental. (Nogueira, 2017, p. 336).

Hasta aquí queda claro el concepto del poder de reforma, la legitimidad, en qué casos procede en Colombia y quién es competente para efectuar el poder de revisión constitucional. Sin embargo, la tarea ahora es definir los límites a los cuales se debe circunscribir el poder de reforma de la Constitución, pues es toda una problemática que enfrenta diferentes criterios al respecto, máxime cuando tiene una estrecha relación con los fines del Estado, ya que debe servir de barrera a los posibles abusos de los poderes públicos, así como garantizar los derechos y libertades de los individuos.

Al tener en cuenta lo anterior, se presentan los argumentos que en teoría constitucional permiten sustentar la importancia o no de imponer límites materiales al poder de reforma desde la postura procedimentalista, planteada por Hans Kelsen (1969), y materialista, definida por Carl Schmitt (2001).

Por un lado, en la teoría de Kelsen (1969) se habla de un poder limitado procedimentalmente, de modo que confía la garantía de los derechos y libertades individuales en el principio democrático de la mayoría parlamentaria. Ello implica que este poder tendría la facultad de modificar cualquier contenido de la Constitución, siempre que se agote el procedimiento especial definido en el mismo texto constitucional. Por otro lado, en la proposición de Schmitt (2001), ese poder se encuentra siempre limitado, tanto procedimental como materialmente. De modo que le está vedado la reforma de determinados contenidos del texto constitucional, convirtiéndose en límites y parámetros de legitimidad para todos los poderes constituidos. Estos solo podrán ser modificados por la actuación de un poder constituyente. En conclusión, las teorías presentadas reconocen de una u otra forma la existencia de unos límites al poder de reforma, ya sean procedimentales o materiales.

Una vez sentadas las bases teórico constitucionales sobre los límites al poder de reforma, que dan cuenta del por qué deben existir esos términos, se analiza a continuación cómo llega esa teoría a la Corte Constitucional, en que método se desarrolla y para efectos de su ilustración, se cita jurisprudencia en la que se ha hecho referencia al tema en comento. 


\section{2. ¿Cómo llega esa teoría a la Corte Constitucional?}

La Corte Constitucional tiene el mandato de conocer de las demandas de inconstitucionalidad que promuevan los ciudadanos contra los actos reformatorios de la Constitución en relación con los vicios de procedimiento (Constitución de Colombia, 1991, artículo 241, n. ${ }^{\circ}$ 1). Ese mandato constitucional supone que los órganos destinatarios de la potestad de reforma tengan ciertas limitaciones y que la Constitución delimite las hipótesis de modificación, excluyendo otras modalidades como su derogatoria, la sustitución en su integridad o su suspensión y desconocimiento ${ }^{1}$.

Por ello, este órgano al ser un poder constituido ha creado la doctrina también llamada teoría o juicio de sustitución. Su finalidad es fundamentar su competencia para la protección de la Carta Magna y así contar con una metodología para controlar el contenido de las reformas a la Constitución.

Esta idea ha sido sostenida desde la Sentencia C-551 de 2003, tras explicar por qué, como sucede con toda actuación del Estado, el poder de reforma de la Constitución está sometido a límites: unos de carácter procedimental, que se refieren a las reglas de deliberación democrática que anteceden a la reforma; y otros, de índole competencial, dirigidos a evitar el exceso en el poder de reforma, de modo que el texto modificado se identifique con el concepto esencial de la Constitución.

Basada en los criterios de los Tribunales Constitucionales de la India y de Alemania, la primera sentencia con la cual la Corte Constitucional abordó el tema ${ }^{2}$, destacó que los límites materiales a la reforma no dependen exclusivamente de la existencia de cláusulas de intangibilidad. Abandonando así la concepción formalista de justicia constitucional propia del positivismo jurídico. Por lo tanto, la Corte afirmó que si bien existen cláusulas intangibles, la identidad y protección de la Constitución no radica en la petrificación de dichas cláusulas, ni en la norma que la desarrollan, sino en los principios que las caracterizan, los cuales se encuentren de forma explícita o implícita en el texto constitucional.

Al implementarse el juicio de sustitución en esa Sentencia hito³, se partió de dos presupuestos básicos: (i) la no autorización para reemplazar, sustituir o derogar la Constitución vigente, permitiendo el artículo 374 tan solo su reforma, además de la clásica distinción entre poder de reforma como poder constituido que debe actuar conforme a los parámetros establecidos y, (ii)

\footnotetext{
${ }^{1}$ Para tener un contexto relacionado con la definición de sustitución y otros fenómenos normativos cercanos que han sido estudiados por la jurisprudencia de la Corte Constitucional, tales como la destrucción, el quebrantamiento, la rotura, la suspensión y la violación de la Constitución, se recomienda el artículo "La Sentencia C-579 de 2013 y la doctrina de la sustitución de la Constitución", del autor Gonzalo Villa Rosas (2014).

${ }^{2}$ Algunos autores como Santiago García Jaramillo y Francisco Gnecco Estrada (2016), consideran que la tesis de la sustitución no tiene su origen en la Sentencia C-551 de 2003, sino que está antecedida de la revisión de reformas constitucionales a la Constitución de 1886. Esto se puede abordar en su artículo "La teoría de la sustitución: De la protección de la supremacía e integridad de la constitución, a la aniquilación de la titularidad del poder de reforma constitucional en el órgano legislativo". Es pertinente aclarar que en este escrito no se compartirá dicha posición.

${ }^{3}$ Término desarrollado por López Medina (2018), en su libro El derecho de los jueces.
} 
reiteró que el poder constituyente es el titular de la soberanía. De ahí que el poder constituyente es en el que puede darse un nuevo ordenamiento constitucional y el poder de reforma no debe usurpar la soberanía popular y desconocer la identidad constitucional plasmada en sus principios y valores.

En estos términos, resaltó que al modificarse la Constitución “debe conservar su identidad en su conjunto a pesar de las reformas que se le introduzcan" (Sentencia C-551, 2003, p. 103). De tal manera que el poder de reforma puede modificar disposiciones del texto sin que supongan una sustitución de la Constitución vigente, pues no se pretende la intangibilidad de ciertas disposiciones, sino la protección de la "identidad constitucional".

Mediante la Sentencia C-1200 de 2003, advirtió los peligros que comporta dicha tesis: la petrificación de la Constitución y el subjetivismo del juez (pretende prevenir que se ejerza un control material e incurra en subjetivismo judicial). En consecuencia, la doctrina adoptada inicialmente matiza e indica que el juicio de sustitución bajo ninguna concepción implica un control de fondo, toda vez que no existen límites materiales implícitos a la reforma constitucional. Y si bien los principios fundamentales o definitorios de una Constitución son importantes para establecer su identidad, no son intocables. No siendo el objetivo la inmutabilidad de principios y valores, sino la vigencia de la Constitución modificada.

La Sentencia señaló así que el acto de reforma es de rango constitucional y por lo tanto no puede ser tratado como una ley. Esto en el entendido de que las leyes ordinarias derivan su validez de la Carta Política, mientras que la norma de reforma por su misma naturaleza puede contrariar disposiciones constitucionales. Precisó que no puede interponerse como limitación a la competencia del poder de reforma la existencia de una disposición supraconstitucional, como sería del caso alegar la intangibilidad de un valor supraconstitucional, siendo por tanto cualquier disposición objeto de modificación.

A partir de la Sentencia C- 970 de 2004, estableció una metodología para aplicar el “juicio de sustitución”, al seguir la estructura propia de un silogismo. En esta destacó que el concepto de sustitución es el que constituye un límite competencial al poder de reforma. Esto es, que la sustitución de la Constitución, en principio, solo puede producirse como consecuencia de la actuación del poder constituyente primario y, por lo mismo, se encuentra sustraída del ámbito competencial del poder de reforma constitucional.

En la Sentencia C-1040 de 2005, la Corte Constitucional declaró inconstitucional la posibilidad de que el Consejo de Estado actuara como legislador extraordinario. El fundamento fue que ello implica una sustitución del postulado de supremacía de la Constitución, elemento que para la Corte es insustituible por el poder de reforma. En efecto, alude a la sustitución de elementos esenciales como el principio de separación de poderes.

En esa oportunidad dilucidó que el juicio de sustitución difiere de los juicios de intangibilidad y de violación de un contenido material de la Constitución Política, toda vez que no pretende verificar si existe una contradicción entre normas como en el control material ordinario, ni 
demostrar la violación de un principio o regla intocable como sucede en el juicio de intangibilidad. Por lo tanto, la sustitución examina si el acto reformatorio introduce un nuevo elemento esencial a la Constitución y si este reemplaza uno originalmente adoptado por el constituyente, además coteja los elementos, no para establecer si son distintos, lo que naturalmente ocurrirá, sino para verificar si son realmente opuestos al punto de resultar incompatibles.

En esa providencia los magistrados Manuel José Cepeda Espinosa, Rodrigo Escobar Gil, Marco Gerardo Monroy Cabra, Humberto Antonio Sierra Porto, Álvaro Tafur Galvis y Clara Inés Vargas Hernández, explicaron cómo el poder de reforma es muy amplio y comprende la adopción de modificaciones importantes e, inclusive, trascendentales. Precisaron que:

No es la importancia, ni son las implicaciones profundas de una reforma, lo que determina si esta supone una sustitución de la Constitución. El fenómeno jurídico se configura cuando un elemento definitorio de la esencia de la Constitución, en lugar de ser modificado, es reemplazado por uno opuesto o integralmente diferente. Así, después de la sustitución de la Carta, como es imposible reconocerla en su identidad básica, no cabe afirmar que la Constitución reformada sigue siendo la misma. (Sentencia C-1040 de 2005).

Por lo anterior, fueron reiterativos en que al Congreso de la República le está vedado sustituir la Constitución, en forma total o parcial, permanente o transitoria. En otras palabras, le está prohibido reemplazar la Constitución por una completamente nueva y diferente. Tampoco puede sustituir la Carta mediante un cambio parcial de tal magnitud que haga imposible, de manera permanente o transitoria, reconocer en la Constitución los elementos esenciales definitorios de su identidad originaria, lo cual no obsta para que el Congreso efectúe reformas importantes para adaptar la Carta a la evolución de la sociedad y responder a las expectativas de los ciudadanos.

Igualmente, es importante resaltar la Sentencia C-588 de 2009, en la cual se refirió a otras figuras por medio de las cuales se podría llegar a configurar un vicio de competencia. Explicó así, el significado de supresión, quebrantamiento y suspensión de la Constitución, aclarando que estos no desnaturalizan el concepto de reforma constitucional. Estableció los requisitos que debe tener una reforma para ser considerada como tal, al apelar al test de efectividad y se refirió a la modificación tácita, como figura utilizada para evadir el procedimiento agravado que implica una reforma constitucional.

Mediante la Sentencia C-141 de 2010, realizó control de constitucionalidad sobre la Ley 1354 de 2009, a través de la cual se pretendía convocar a un referendo constitucional. Precisó que si bien el pueblo es el titular de la soberanía, cuando actúa en virtud de los mecanismos de reforma constitucional, debe hacerlo dentro de los límites procedimentales y competenciales establecidos. De ahí que carece de competencia para sustituir la Constitución Política.

Explicó que no se puede calificar en este evento su actuación como expresión del constituyente, máxime, cuando el procedimiento seguido para la aprobación del referendo implica que el Congreso mediante una ley incorpore la convocatoria, viéndose expuesta la propuesta del grupo de ciudadanos a circunstancias que alteren y desconozcan su voluntad. 
Indicó que el único mecanismo previsto en la Constitución de 1991, que no está sujeto a límites competenciales, es la Asamblea Nacional Constituyente, siempre que sea convocada para emitir una nueva Constitución, advirtiendo que aun en dicho evento existen límites, los cuales no emanarían de la Constitución sustituida sino de las normas imperativas de derecho internacional y los convenios internacionales de derechos humanos (Constitución de Colombia, 1991, artículo 94).

Ahora, la Sentencia C-288 de 2012 contiene la decisión de la Corte acerca de la constitucionalidad del Acto Legislativo n. ${ }^{\circ} 03$ de 2011, mediante el cual se estableció el criterio de sostenibilidad fiscal. En ella indicó como el examen que realiza sobre los defectos en la formación del acto no excluye los eventuales vicios en el ejercicio del poder de reforma, habida cuenta que toda Constitución democrática, aun cuando no tenga expresamente cláusulas pétreas, impone límites de competencia al poder de reforma del constituyente derivado, por ser un poder constituido y no el poder constituyente originario.

Las disposiciones de las providencias señaladas han sido reiteradas en sentencias más recientes, como la C-579 de 2013, C-577 de 2014, C-699 de 2016, C-332 de 2017 y C-94 de 2017, entre otras. Estas son tan solo algunas de las proferidas por la Corte Constitucional con motivo de las demandas ciudadanas contra actos reformatorios de la Constitución ${ }^{4}$.

Lo anterior permite señalar que aun cuando la Corte Constitucional no lo admita, se enmarca en la doctrina que alude a la existencia de límites materiales implícitos o no expresos al poder de reforma. Para ello, ha acogido la postura de Schmitt (2001), tras acertar que solo el poder constituyente es el que determina las decisiones políticas fundamentales, puesto que las reformas son válidas en la medida que se garantice la identidad y continuidad de la Constitución, al tener en cuenta que la facultad de reformarla no contiene la facultad de dar una nueva Constitución.

En este punto es pertinente traer a colación la definición que Luigi Ferrajoli (2001) ha dado a la Constitución, en el entendido que:

No solo representa la voluntad popular sino los derechos de todos, incluso frente a la voluntad del pueblo. La función de la Constitución no es expresar la existencia de un demos, es decir, de una homogeneidad cultural, identidad colectiva o cohesión social, sino garantizar la convivencia pacífica entre sujetos e intereses. (Ferrajoli, 2001, p. 41).

A continuación se realiza la tercera parte anunciada, con el propósito de determinar si el constituyente secundario se excedió en el ejercicio de sus competencias de reforma de la Carta Política, por suprimir o anular alguno de sus elementos definitorios en el Acto Legislativo 01 de 2017, no sin antes dejar por sentado que tanto la teoría de la sustitución de la constitución ${ }^{5}$,

\footnotetext{
${ }^{4}$ Se recomienda el artículo "La sentencia C-579 de 2013 y la doctrina de la sustitución de la Constitución," del autor Gonzalo Villa Rosas (2014), para efectos de hacer un seguimiento a la línea jurisprudencial del juicio de sustitución. En este estudio solo se hizo alusión a aquellas que permitían establecer criterios básicos para definir los postulados de esa doctrina.

${ }^{5}$ Ver referencia línea jurisprudencial sobre la metodología del juicio de sustitución.
} 
como el cumplimiento del bloque de constitucionalidad, son claves en la comprensión del problema jurídico propuesto.

\section{3. ¿Cómo se analizaron los postulados que componen la Jurisdicción Especial para la Paz por parte de la Corte Constitucional?}

El Acto Legislativo 01 de 2017 fue expedido con base en las atribuciones que le fueron conferidas al Congreso de la República en el Acto Legislativo 01 de 2016. Este último, dispone que los instrumentos dictados con fundamento en dichas potestades deben ser objeto de un control diferente. De ahí que la naturaleza y el alcance del control de constitucionalidad de los actos legislativos proferidos en virtud del procedimiento legislativo especial para la paz, se caracterizan por ser jurisdiccional, automático, limitado, único, participativo, abreviado y posterior a la vigencia del respectivo Acto Legislativo (Sentencia C-674, 2017) (entiéndase por vigencia el momento en el que empieza a surtir efectos).

De otro lado, en la medida en que el análisis específico recae sobre un acto reformatorio de la Constitución, no es procedente su revisión material sino únicamente un examen competencial que se enfoca en establecer si el constituyente secundario se desbordó en el ejercicio de sus competencias reformatorias al suprimir, eliminar o sustituir alguno de los componentes esenciales del ordenamiento superior.

En este orden de ideas, tiene como referente de control los elementos fundamentales y transversales de la Constitución Política y el ejercicio analítico se encamina a establecer si tales piezas fueron eliminadas al seguir los estándares metodológicos fijados por la Corte Constitucional, como ya se señaló, el respectivo juicio de sustitución.

No obstante, el juicio de sustitución que se efectúa tiene algunas particularidades derivadas; primero, de las facultades normativas especiales con fundamento en las cuales fue expedida la reforma constitucional; segundo, de que esta última se inscribe en un escenario de transición hacia la paz, como un eje fundacional y objetivo común de la humanidad, y tercero, que este instrumento consagra un sistema integral y cohesionado de verdad, justicia, reparación y no repetición.

$\mathrm{Al}$ respecto, se presenta la Tabla 1 para efectos de señalar los parámetros que diferencian los juicios ordinarios de sustitución y el juicio de sustitución que respecto de la Jurisdicción Especial para la Paz se vienen implementando en el escrutinio judicial desarrollado por la Corte Constitucional: 
Tabla 1. Parámetros entre el juicio ordinario de sustitución y el juicio de sustitución de la JEP

\begin{tabular}{|c|c|c|}
\hline Parámetros & Juicio ordinario de sustitución & $\begin{array}{l}\text { Juicio de Sustitución Jurisdicción } \\
\text { Especial para la Paz }\end{array}$ \\
\hline \multirow[b]{2}{*}{ Revisión } & $\begin{array}{l}\text { Recae sobre aquellas que hayan sido in- } \\
\text { dividualizadas e identificadas previamente } \\
\text { en una demanda de inconstitucionalidad. }\end{array}$ & $\begin{array}{l}\text { Recae sobre todas las disposiciones del } \\
\text { Acto Legislativo } 01 \text { de } 2017 .\end{array}$ \\
\hline & $\begin{array}{l}\text { Control concreto: la revisión es rogada } \\
\text { y se activa con necesidad de cuestiona- } \\
\text { miento público de validez del acto. }\end{array}$ & $\begin{array}{l}\text { Control automático: la revisión es oficiosa } \\
\text { y se activa sin necesidad de cuestiona- } \\
\text { miento público de validez del acto. }\end{array}$ \\
\hline $\begin{array}{l}\text { Parámetros } \\
\text { de control }\end{array}$ & $\begin{array}{l}\text { El examen se efectúa tomando como re- } \\
\text { ferente de análisis los componentes esen- } \\
\text { ciales de la Constitución, identificados } \\
\text { previamente en una acción de inconstitu- } \\
\text { cionalidad. }\end{array}$ & $\begin{array}{l}\text { El examen se efectúa identificando en la } \\
\text { reforma los elementos que puedan apa- } \\
\text { recer como problemáticos desde una } \\
\text { perspectiva de sustitución y luego con- } \\
\text { frontarlos con aquellos ejes esenciales de } \\
\text { la Carta Política que podrían quedar com- } \\
\text { prometidos, de suerte que se pueda dejar } \\
\text { establecida la validez del Acto legislativo } \\
01 \text { de } 2017 \text {. }\end{array}$ \\
\hline $\begin{array}{l}\text { Ejercicio } \\
\text { analítico }\end{array}$ & $\begin{array}{l}\text { La controversia se estructura en función } \\
\text { de las acusaciones planteadas por el ac- } \\
\text { cionante y eventualmente por los intervi- } \\
\text { nientes. De modo que el examen apunta a } \\
\text { evaluar tales } \text { cargos }^{6} \text {. }\end{array}$ & $\begin{array}{l}\text { La controversia se estructura en abstrac- } \\
\text { to, a la validez de la reforma. De modo que } \\
\text { no se configura en función de los señala- } \\
\text { mientos formulados que puedan ser for- } \\
\text { mulados. }\end{array}$ \\
\hline
\end{tabular}

Fuente: la autora de acuerdo a la Sentencia C- 674, 2017, p. 251.

Así las cosas, quedó claro que tratándose de actos legislativos de esta naturaleza su control tiene características diferentes, al ser automático, integral y único de constitucionalidad.

De igual manera, el Acto Legislativo 01 de 2017 establece el marco jurídico para un escenario transicional específico, en el contexto de un proceso de paz. Se advierte que el escrutinio judicial debe ajustarse a la naturaleza del mismo, al tener en cuenta dos hechos constitucionalmente relevantes que repercuten directamente en el alcance del control competencial, así:

1. Flexibilización del escrutinio judicial en los escenarios de transición. Al respeto, la Corte indica que:

Se trata de escenarios que por su propia naturaleza exigen transformaciones sustantivas en la estructura institucional y en las dinámicas del funcionamiento social y que, además, se encuentran precedidos de delicados procesos transaccionales y de negociación política que revisten un alto nivel de complejidad, orientados a la terminación del conflicto armado y a la consecución de la paz.

${ }^{6}$ Es pertinente tener presente que en la Sentencia C-1200 de 2003 se estableció que la carga argumentativa para demostrar que la pretendida reforma sustituyó la Constitución, es del ciudadano demandante y solo sobre esos cargos se pronunciará la Corte. 
En ese contexto, el escrutinio parte del reconocimiento del especial margen de apreciación con el que cuentan los actores políticos para rediseñar las estructuras estatales y para reconfigurar la vida política, económica y social. Lo cual, en últimas, implica una flexibilización del juicio de sustitución. (Sentencia C-579, 20137\% Sentencia C-699, 2016).

2. El juez debe articular en el juicio de sustitución las consideraciones relativas al escenario transicional, mediante un análisis individualizado de las medidas objeto de control a la luz de esta circunstancia y de la paz como principio, valor y derecho. Este punto fue explicado por la Corte Constitucional en la Sentencia C-674 de 2017 en los siguientes términos:

Esto significa que la sola invocación de la paz no puede servir como justificación de las alteraciones a los diseños del constituyente primario, y que esta constituye un referente ineludible del escrutinio judicial en los escenarios de transición, mas no una razón de Estado a la luz de la cual resulte imperativo para este Tribunal validar cualquier medida que se ampare en una invocación global a la paz (p. 265).

En este orden de ideas, se trata de una variable en el ejercicio analítico que realiza la Corte Constitucional que solo puede ser justificada dentro del marco de un sistema de justicia transicional. De ahí que el estudio de la justificación de dichos medios implica primero el análisis de la justificación de tal sistema.

Ahora bien, es pertinente indicar que la Corte en materia de paz ya se había pronunciado en la Sentencia C-579 de $2013^{8}$. En esa providencia realizó un análisis estricto de sustitución y declaró la exequibilidad del inciso 4 del artículo 1 del Acto Legislativo 1 de 2012, denominado Marco Jurídico para la Paz. En este, se buscó implementar mecanismos a través de los cuales fuese posible satisfacer los derechos de las víctimas a la verdad, la justicia y la reparación y al mismo tiempo a la necesidad de brindar un tratamiento penal especial a personas que han participado activamente en el conflicto armado colombiano y que han dejado las armas. En efecto, la Corte en la Sentencia señaló que:

Los componentes del deber de garantía de los derechos, específicamente del compromiso de investigación, juzgamiento y en su caso sanción de las graves violaciones a los derechos humanos y al derecho internacional humanitario, pueden sufrir limitaciones en un ejercicio de ponderación, cuando ellas resulten en ganancias mayores en términos de otros principios constitucionales como la obtención de la paz y la construcción de la verdad en un contexto de conflicto. (Sentencia C-579, 2013, p. 308).

Como se dijo anteriormente, el juicio de sustitución es una metodología creada por la Corte Constitucional en el marco de la constitucionalización del derecho que incrementa el poder de los jueces frente a la facultad de reforma. Esta implica trabajar en lo siguiente: i) premisa

\footnotetext{
${ }^{7}$ Ver referencia de la Sentencia. Allí se amplía la visión de la Corte Constitucional sobre la flexibilización del escrutinio judicial en los escenarios de transición.

${ }^{8}$ También lo hizo con la Ley de Justicia y Paz, pero ello no será objeto de pronunciamiento en este artículo.
} 
mayor: determina si el elemento presuntamente sustituido, efectivamente corresponde a un eje definitorio de la carta política; ii) premisa menor: analiza la reforma constitucional y su impacto en dicho eje definitorio o elemento axial; y, iii) conclusión: determina si la reforma sustituye la identidad de la Constitución.

A continuación, se amplían los conceptos acabados de mencionar. Para ello se acude a apartes de la Sentencia C-674 de 2017:

- Premisa mayor del juicio de sustitución; es decir, los estándares con respecto a los cuales se evalúa la competencia del constituyente secundario para reformar el ordenamiento superior, teniendo en cuenta que aunque el Acto Legislativo 01 de 2017 exige un control integral, tratándose de un control automático, resulta indispensable que, en cada caso, la Corte precise el objeto de la litis constitucional identificando los componentes medulares de la Carta Política en torno a los cuales se puede estructurar el juicio de sustitución.

Así las cosas, previamente se seleccionan aquellos pilares que serán utilizados en el escrutinio judicial, verificando, por un lado, que dicho referente tenga, al menos prima facie, el status de principio medular de la Carta Política, y por otro, que tenga un vínculo sustantivo con las materias reguladas en el acto legislativo objeto de revisión. (p. 267).

Lo anterior, en el sentido que constituyen una pieza irremovible del ordenamiento superior. En especial, si se considera que los elementos esenciales de la Constitución tienen la estructura de principios, entonces dichos elementos admiten restricciones. Adicional a ello, a la hora de garantizar los derechos humanos y adelantar las acciones pertinentes para atender sus graves violaciones (investigar, juzgar y sancionar), se debe tener presente que estos tienen la naturaleza de principios. En la medida en que:

(i) Dan fundamento o valor al Estado de derecho mismo, a través de la condensación de valores éticos y de justicia; (ii) contemplan obligaciones generales que no generan obligaciones rígidas sino que buscan alcanzar su más alta satisfacción; (iii) tanto en el ámbito internacional como en la Constitución se contemplan como principios. (Villa Rosas, 2014, pie de página 240, p. 86).

Al seguir con la ampliación de conceptos, la Sentencia C-674 de 2017 alude a la premisa mayor en los siguientes términos:

En este sentido, la Corte encuentra que la presente reforma constitucional contiene dos ejes temáticos: por un lado, se establece una nueva institucionalidad encargada de operar los instrumentos de transición, a través de la Comisión para el Esclarecimiento de la Verdad, la Convivencia y la No Repetición, la Unidad de Búsqueda de Personas dadas por Desaparecidas en el contexto y en razón del conflicto armado y la Jurisdicción Especial para la Paz; y por otro, se crean las herramientas de verdad, justicia, reparación y no repetición.

En este orden de ideas, en relación con el primer componente, esto es, las modificaciones a la estructura del Estado, la controversia constitucional se estructura en función de los principios de separación de poderes, de independencia judicial y de supremacía constitucional, ya que se trata, según la jurisprudencia de este Tribunal, de principios fundantes que irradian toda la Constitución 
de 1991 y que por tanto no son susceptibles de ser eliminados o sustituidos por el constituyente secundario, y porque, además, estos principios se refieren directamente a la forma en que debe estructurarse el poder político.

Por su parte, en relación con el segundo componente del Acto Legislativo 01 de 2017, esto es, los instrumentos de verdad, justicia, reparación y no repetición, los elementos definitorios que son empleados en el juicio de sustitución son el deber del Estado de investigar, juzgar y sancionar las graves violaciones a los derechos humanos y las infracciones al Derecho Internacional Humanitario, el deber del Estado de asegurar los derechos de las víctimas a la verdad, la justicia y la reparación integral y la garantía del juez natural como componente del derecho al debido proceso. (pp. 267-268).

- Premisa menor del juicio de sustitución; es decir, se precisan los contenidos normativos sobre los que debe recaer el escrutinio judicial. La Corte puntualiza que únicamente puede recaer sobre aquellos elementos de los que quepa predicar los supuestos de dicho juicio. Por esa razón, se refiere a dos núcleos temáticos regulados en el acto objeto de control; esto es, las modificaciones a la estructura institucional del Estado, y los instrumentos de verdad, justicia, reparación y no repetición que deben ser operados en el actual escenario de transición, en el entendido de que el análisis de la competencia se extenderá a toda esta regulación considerada en su conjunto (acabados de referir en la premisa mayor). (Sentencia C-674 de 2017).

- Conclusión: una vez identificados los elementos esenciales de la Carta Política que sirven como referentes del juicio de sustitución y acotado el objeto de la controversia constitucional, se evalúa la validez de la normatividad objeto de revisión. Estableciendo si algunos de los citados ejes transversales del ordenamiento superior fueron sustituidos, eliminados, suprimidos o quebrantados por el Acto Legislativo 01 de 2017. Partiendo entonces de estos elementos, se arribará a la conclusión del juicio de sustitución. (Sentencia C-674 de 2017, p. 269).

En resumen, la metodología para el ejercicio del control de constitucionalidad en relación con cargos por sustitución, corresponde a un esquema deductivo compuesto por tres elementos: una premisa mayor, una premisa menor y una conclusión. Esta es una operación básica, que en el pensamiento de Robert Alexy (2007) correspondería a la subsunción.

Sobre la base de los argumentos previamente planteados, se enmarca la problemática inicialmente mencionada sobre la identificación de si se trató de una reforma o sustitución, por ello a continuación se abarcará ese interrogante, no sin antes destacar que se trata de un tema de relevancia, en la medida en que se trasladaron las facultades de la justicia ordinaria para juzgar y condenar a quienes son victimarios del conflicto, a la Jurisdicción Especial para la Paz.

De los argumentos de la Sentencia C-674 de 2017, la Corte reconoce que el Acto Legislativo, que da vida a la JEP, surge de la responsabilidad de poder derivada en el Legislativo, para que este trabaje a favor del principio y fin constitucional de la paz, para la superación de un panorama de degradada violencia a la que llevó la realización de este conflicto, como se ha planteado anteriormente. En esta oportunidad, también se reconoce que esa labor se puede hacer en razón 
de la capacidad jurídica del Estado para diseñar, frente a unas condiciones específicas, procesos de juzgamiento denominados de justicia transicional, por medio de la cual, y de manera temporal, se asuma esa función judicial.

Particularmente, el vínculo existente entre el desarrollo normativo planteado en el acto de reforma y el acuerdo final es para la Corte Constitucional un objetivo, estricto y suficiente, pues no se regulan aspectos diferentes o que rebasen el ámbito de aquellos asuntos imprescindibles para el proceso de la implementación. Además, porque las disposiciones aprobadas responden de manera precisa a lo pactado en los capítulos 3 y subsiguientes del Acuerdo Final; y, por último, entre las materias objeto de regulación y el contenido del Acuerdo Final se advierte un grado de estrecha proximidad.

En cuanto al control formal, se tiene en cuenta lo previsto por el Acto Legislativo 01 de 2016, como lo son esos requisitos especiales que introduce los denominados: conexidad material $^{9}$, teleológica ${ }^{10}$, habilitación temporal ${ }^{11}$ y competencial ${ }^{12}$, más los generales, dispuestos por la Constitución en su Título XIII, artículo 379 y el Reglamento del Congreso. En el comunicado n. ${ }^{\circ} 55$ del año 2017, la Corte Constitucional expresó:

Respecto de los vicios competenciales derivados de una posible sustitución de la Constitución, la Corte precisó que la paz fue asumida como uno de los principales propósitos constituyentes y, en esa medida, el rigor del juicio de sustitución de las reformas adoptadas por el Congreso en contextos de transición dirigidos a su realización, debe atenuarse, aminorarse o moderarse de manera que sea posible, con ese propósito, introducir modificaciones, incluso profundas, al ordenamiento constitucional. (p. 17).

Se trata entonces de una reforma constitucional que cumple con las condiciones formales de su trámite, y cuyo contenido material no condiciona el surgimiento de un escenario de conflicto constitucional. En el comunicado acabado de mencionar, la Corte Constitucional precisó:

(i) que debían tenerse en cuenta los requerimientos generales del juicio de sustitución relativos, entre otras cosas, a la identificación de los ejes definitorios de la Carta a partir de una lectura completa, sistemática y transversal de la misma, así como a la improcedencia de confundir los ejes definitorios con manifestaciones específicas y accidentales de los mismos.

En adición a ello, sostuvo (ii) que es también necesario reconocer que, al juzgar los límites competenciales del Congreso en contextos de transición hacia la paz, debe reconocerse una extendida atribución para emprender reformas que, en otros contextos, no estarían comprendidos por el

\footnotetext{
${ }^{9}$ El Congreso a través del Fast track solo puede regular materias que tengan una conexión clara, estrecha y directa con el Acuerdo Final. Se observa que el mecanismo abreviado es utilizado para garantizar la implementación de lo pactado.

${ }^{10}$ Las reformas que se tramiten mediante el procedimiento legislativo especial para la paz deben tener como propósito facilitar y asegurar la implementación y el desarrollo normativo del acuerdo.

${ }^{11}$ Deber de expedir actos que son objeto de trámite en el Fast track (6 meses) a partir de la vigencia del Acto Legislativo 01 de 2016, o de su prorroga, por un periodo adicional de 6 meses, previa comunicación formal del Gobierno Nacional al Congreso de la República.

${ }^{12}$ Los proyectos de Acto Legislativo que se tramiten a través del Fast track deben ser iniciativa exclusiva del Gobierno Nacional Literal a del Acuerdo Legislativo 01 de 2016.
} 
poder de revisión constitucional asignado al Congreso. (Corte Constitucional, Comunicado n. ${ }^{\circ} 55$ de 2017, p. 17).

Así las cosas, queda claro que el trámite de reforma a la Constitución es una facultad que se atribuye al Congreso de la República, a la Asamblea Constituyente, y al Pueblo; y que, por su parte, la sustitución descansa exclusivamente en este último, al ser el constituyente primario. De ahí que en el análisis jurídico de la constitucionalidad de la JEP, y su juicio sobre la posible sustitución de la Constitución, al ser este introducido en la Constitución vía Acto Legislativo, se encuentra que esta fue una reforma de Constitución basada en principios que guardan la identidad de esta y se condicionan a una situación política, social y jurídica, padecida por muchos años en Colombia y no una sustitución de la misma.

\section{Conclusión}

El poder de reforma de la Constitución está sometido a límites. Estos devienen de la facultad que otorga la misma Constitución para reformarse, más no para sustituirse o modificarse por otra que no respalde su identidad material. En ese sentido, la Constitución no establece cláusulas pétreas, pero si límites implícitos a la reforma de la Constitución, los cuales se denominan vicios de competencia que autorizan a reformarla, pero no a sustituirla. Unos de carácter procedimental, que se refieren a las reglas de deliberación democrática que anteceden a la reforma. $Y$ otros de índole competencial (material), dirigidos a evitar el exceso en el poder de reforma, de modo que el texto modificado se identifique con el concepto esencial de la Constitución. Para ello, (i) analiza principios y valores que la Constitución contiene y, (ii) no desconoce los preceptos del artículo 94 de la Constitución Política, al tratarse de derechos inherentes al ser humano.

En el marco de la jurisprudencia que ha sido proferida por la Corte Constitucional en lo relacionado a la teoría de límites a la reforma constitucional, se identificó que a partir del año 2003 hasta la actualidad, se desarrolla el pensamiento de Carl Schmitt (2001). En el entendido que se trata de una facultad de reformar la Constitución sin que con ello se altere la identidad y continuidad de la misma.

Otro de los puntos que permiten aseverar que la Corte Constitucional actúa bajo la postura de Schmitt (2001) son los siguientes: i) el hecho de que reiteradamente indique que la reforma de la Constitución no puede ser destrucción de la misma, lo cual implica, lógicamente, que no otorga competencia para sustituirla o eliminarla, y ii) la distinción entre poder constituyente y poder de reforma, en la medida en que solo el primero cuenta con la competencia para reformar los elementos definitorios que le dan identidad a la Constitución, y el segundo se encuentra limitado por tales elementos, escapando de su competencia la modificación de ellos.

La constitucionalización del ordenamiento jurídico incrementa el poder de los jueces frente a la reforma de la Constitución. De ahí que, en cuanto a la competencia, la Corte Constitucional debe controlar que el Gobierno, el Congreso o los ciudadanos no excedan esos límites. Advierte que no son solo los vicios de procedimiento (que son también límites), sino que debe controlar 
también los límites competenciales (criterios objetivos como los principios y valores constitucionales, implícitos o materiales), con los cuales se mantenga la identidad constitucional.

Para ello, existe la doctrina o Teoría de la Sustitución. Este método propio de la Corte Constitucional permite mediante tres elementos estudiar el control constitucional sobre el ejercicio del poder de reforma. Estos son: premisa mayor, premisa menor y conclusión. La primera en el entendido de que toda modificación a la Constitución que reemplace un aspecto definitorio de la identidad de la Constitución, es una sustitución. La segunda, en la medida en que se establezca cuál es el alcance jurídico en relación con los elementos definitorios identificadores de la Constitución, a partir de los cuales se han aislado los parámetros normativos para el control. La tercera y última, es la comparación de la premisa menor con la premisa mayor. Allí se verifica si la reforma reemplaza un elemento definitorio identificador de la Constitución por otro integralmente diferente. Lo anterior, para advertir situaciones que contradicen los fundamentos normativos que subyacen a las reglas de competencia que rigen su ejercicio.

En el caso particular objeto de análisis, la Corte tuvo como premisa mayor el compromiso del Estado Social y Democrático de Derecho con el respeto, protección y garantía de los derechos de las víctimas. En cuanto a la premisa menor, la búsqueda de la paz estable y duradera. Y como conclusión, precisó que la adopción del Acto Legislativo 01 de 2017 no implica el reemplazo del elemento esencial de la Constitución definido en la premisa mayor del juicio de sustitución, porque el grado de no satisfacción o de restricción de dicho elemento esencial, se justifica en razón a la importancia de alcanzar el principio que persigue el acto de reforma.

Así las cosas, en la Sentencia C-674 de 2017 relacionada con el Acto Legislativo 01 de 2017 proferido por parte del Congreso de la República, se destaca que con la aprobación de la Jurisdicción Especial para la Paz se introduce en la Constitución vía Acto Legislativo una nueva Jurisdicción y, con ello, no se está sustituyendo la misma sino que opera una reforma.

No obstante, es pertinente destacar que aun tratándose de la Jurisdicción Especial para la Paz se deben respetar los límites del poder de reforma. En la medida en que si bien es cierto la circunstancia de que el acto legislativo crea una institucionalidad y unos instrumentos llamados a operar en un escenario transicional, también lo es que no se traduce en un relajamiento o en un debilitamiento automático y general del escrutinio judicial, sino en la flexibilidad del ejercicio analítico, para determinar si las medidas objeto de control constituyen un aporte o una contribución necesaria y efectiva para la construcción de una paz estable y duradera.

Lo anterior significa que la sola invocación de la paz no puede servir como justificación de las alteraciones a los diseños del constituyente primario, y que esta constituye un referente ineludible del escrutinio judicial en los escenarios de transición, más no una razón a la luz de la cual resulte imperativo para la Corte Constitucional validar cualquier medida que se ampare en una invocación global a la paz.

De este modo, el efecto de la calificación jurídica del Acto Legislativo 01 de 2017 articula en el juicio de sustitución las consideraciones relativas al escenario transicional, mediante un 
análisis individualizado de las medidas objeto de control a la luz de esta circunstancia, pero sin dejar de lado la rigurosidad que lo identifica. Ello por cuanto, i) se desarrolla mediante paramentos un poco diferentes a los juicios ordinarios de sustitución, y ii) se trata de escenarios que por su propia naturaleza exigen transformaciones sustantivas en la estructura institucional y en las dinámicas del funcionamiento social, y que, además, se encuentran precedidos de delicados procesos transaccionales y de negociación política que revisten un alto nivel de complejidad, orientados a la terminación del conflicto armado y a la consecución de la paz.

En suma, en el marco de una visión teórica constitucional de los límites al poder de reforma en el contexto del Acto Legislativo 01 de 2017, se protege esa identidad constitucional, al tener presente esos factores reales y efectivos de poder que rigen en el país. De manera que las implicaciones de alcanzar la paz demuestran que, pese a que la identidad constitucional es la misma establecida por el constituyente primario, el espíritu de la Constitución ha cambiado, en el entendido de las condiciones sociales de un país que por más de cincuenta años ha padecido un conflicto armado interno y que necesariamente requiere de unas transformaciones políticas para trasegar de la guerra a la paz. En ese enfoque es imperante que ese juicio de sustitución por parte del máximo juez constitucional tenga siempre en cuenta esos principios normativos enfrentados, además con esa realidad, que claramente no se moldean fácilmente pero que a través de la flexibilidad del escrutinio judicial es posible alcanzar.

\section{Referencias}

Alexy, R. (2007). Teoría de la argumentación jurídica. La teoría del discurso racional como teoría de la fundamentación jurídica. (1. ${ }^{a}$ ed. Ampliada), Lima, Perú: Editorial Palestra.

Constitución Política de Colombia de 1991 (2016). 1. ${ }^{a}$ Ed. Bogotá, Colombia. Legis.

Colombia. Poder Legislativo (2016, 26 de junio). Acuerdo Final para la Terminación del Conflicto y la Construcción de una Paz Estable y Duradera. Recuperado de https://www.refworld.org.es/ docid/5a8744d54.html

Corte Constitucional de Colombia (2017). Comunicado n. ${ }^{\circ} 55$, p.17. Recuperado de https://www.corteconstitucional.gov.co/comunicados/No.\%2055\%20comunicado\%2014\%20de\%20noviembre\%20 de\%202017.pdf

Ferrajoli, L. (2001). Pasado y futuro del estado de derecho. Revista Internacional de Filosofía Política, (17), 31-45. Recuperado de http://e-spacio.uned.es/fez/eserv.php?pid=bibliuned:filopoli-2001-17$0011 \& \mathrm{dsID}=\mathrm{pdf}$

García Jaramillo, S. \& Gnecco Estrada, F. (2016). La teoría de la sustitución: De la protección de la supremacía e integridad de la Constitución, a la aniquilación de la titularidad del poder de reforma constitucional en el órgano legislativo. Vniversitas, 65 (133), 59-104. https://doi.org/10.11144/Javeriana.vj133.tsps

Kelsen, H. (1969). Teoría general del derecho y el Estado (3a ed.). México: Universidad Nacional Autónoma de México. 
López Medina, D. (2018). La línea jurisprudencial: Análisis dinámico de precedentes. (Capítulo 5). En El derecho de los jueces. 17 ed. (pp. 139-192). Bogotá, Colombia: Legis.

Nogueira Alcalá, H. (2017). Poder constituyente, reforma de la Constitución y control jurisdiccional de constitucionalidad. México. Cuestiones Constitucionales. Revista Mexicana de Derecho Constitucional, 36 (c), 327-349. Recuperado de http://www.scielo.org.mx/pdf/cconst/n36/1405-9193cconst-36-327.pdf

Schmitt, C. (2001). Teoría de la Constitución. Madrid, España: Alianza Editorial.

Sentencia C-674 (2017). Corte Constitucional de Colombia. Magistrado Ponente: Luis Guillermo Guerrero Pérez.

Sentencia C-332 (2017). Corte Constitucional de Colombia. Magistrado Ponente: Antonio José Lizarazo Ocampo. [En relación con el procedimiento legislativo especial para la paz].

Sentencia C-112 (2017). Corte Constitucional de Colombia. Magistrado Ponente: Antonio José Lizarazo Ocampo. [En relación con la reforma constitucional al equilibrio de poderes].

Sentencia C-699 (2016). Corte Constitucional de Colombia. Magistrado Ponente: María Victoria Calle Correa. [En relación con el procedimiento legislativo especial para la paz].

Sentencia C-373 (2016). Corte Constitucional de Colombia. Magistrados ponentes: Alejandro Linares Cantillo y Gabriel Eduardo Mendoza Martelo. [En relación con la reforma al equilibrio de poderes y reajuste institucional].

Sentencia C-285 (2016). Corte Constitucional de Colombia. Magistrado Ponente: Luis Guillermo Guerrero Pérez. [En relación con la reforma al equilibrio de poderes y reajuste institucional].

Sentencia C-577 (2014). Corte Constitucional de Colombia. Magistrado Ponente: Martha Victoria Sáchica Méndez. [En relación con el Marco Jurídico para la Paz].

Sentencia C-579 (2013). Corte Constitucional de Colombia. Magistrado Ponente: Jorge Ignacio Pretelt Chaljub. [En relación con el Marco Jurídico para la Paz].

Sentencia C-470 (2013). Corte Constitucional de Colombia. Magistrado Ponente: Alberto Rojas Ríos. [En relación con el régimen constitucional de las regalías].

Sentencia C-1056 (2012). Corte Constitucional de Colombia. Magistrado Ponente: Nilson Pinilla Pinilla. [En relación con el régimen de inhabilidades de los congresistas].

Sentencia C-249 (2012). Corte Constitucional de Colombia. Magistrado Ponente: Juan Carlos Henao Pérez. [En relación con el régimen jurídico de las personas vinculadas de manera provisional a la administración pública].

Sentencia C-288 (2012). Corte Constitucional de Colombia. Magistrado Ponente: Luis Ernesto Vargas Silva. [En relación con el incidente de impacto fiscal].

Sentencia C-170 (2012). Corte Constitucional de Colombia. Magistrado Ponente: Jorge Iván Palacio Palacio. [En relación con la supresión de la autonomía del órgano regulador del servicio público de televisión].

Sentencia C-141 (2010). Corte Constitucional de Colombia. Magistrado Ponente: Humberto Antonio Sierra Porto. [En relación con el referendo reeleccionista para permitir un segundo mandato presidencial consecutivo]. 
Sentencia C-588 (2009). Corte Constitucional de Colombia. Magistrado Ponente: Gabriel Eduardo Mendoza Martelo. [En relación con los empleados vinculados como provisionales a la administración pública].

Sentencia C-757 (2008). Corte Constitucional de Colombia. Magistrado Ponente: Rodrigo Escobar Gil. [En relación con la moción de censura].

Sentencia C- 370 (2006). Corte Constitucional de Colombia (2004). Magistrados ponentes: Manuel José Cepeda Espinosa; Jaime Córdoba Triviño; Rodrigo Escobar Gil; Marco Gerardo Monroy Cabra; Álvaro Tafur Galvis; Clara Inés Vargas Hernández.

Sentencia C-1040 (2005). Corte Constitucional de Colombia. Magistrados ponentes: Manuel José Cepeda Espinosa, Rodrigo Escobar Gil, Marco Gerardo Monroy Cabra, Humberto Antonio Sierra Porto, Álvaro Tafur Galvis y Clara Inés Vargas Hernández. [En relación con la figura de la reelección presidencial].

Sentencia C-970 (2004). Corte Constitucional de Colombia. Magistrado Ponente: Rodrigo Escobar Gil. [En relación con la habilitación legislativa dada al presidente en materias que son reserva de Ley].

Sentencia C-1200 (2003). Corte Constitucional de Colombia. Magistrados ponentes: Manuel José Cepeda y Rodrigo Escobar Gil. [En relación con la implementación del sistema acusatorio].

Sentencia C-551(2003). Corte Constitucional de Colombia. Magistrado Ponente: Eduardo Montealegre Lynett [En relación con los referendos].

Villa Rosas, G. (2014). La Sentencia C-579 de 2013 y la doctrina de la sustitución de la constitución. En K. Ambos (Coord.), Justicia de Transición y Constitución: Análisis a la Sentencia C-579 de 2013 de la Corte Constitucional, (pp.22-101). Bogotá, Colombia: Editorial Temis. Recuperado de https://www.kas. de/c/document_library/get_file?uuid=33114c11-fa4a-5789-28b5-2f44056203f1\&groupId=252038

Zagrebelsky, G. (1988). Manuale di diritto Costituzionale. $2^{\text {a }}$. ed., Turín, Utet. [Versión en español: La Constitución y sus normas, (pp.67-92). En Carbonell, M. (comp.) Teoría de la Constitución, Ensayos escogidos (2000). México: Porrúa-unam.

Bibliografía recomendada

Ambos, K., Cote Barco, G. E., Ibáñez Gutiérrez, C., Sánchez, N. C., Tarapués Sandino, D. F., Villa Rosas, G. \& Zuluaga T., J. E. (2014). El Marco Jurídico para la Paz y el Análisis Estricto de Sustitución de la Constitución realizado en la Sentencia C-579 de 2013, en K. Ambos (Coord.) Justicia de Transición y Constitución, (pp.197-271). Bogotá, Colombia: Temis/Cedpal/Konrad-Adenauer-Stiftung. Recuperado de http://cedpal.uni-goettingen.de/data/publicaciones/2014/LibroMJP.pdf

Cajas Sarria, M. (2004). La reforma constitucional: Límites de la corte al congreso. Precedente. Revista Jurídica, (-), 13-48. https://doi.org/10.18046/prec.v0.1412

Jaramillo Giraldo, J. (2013, enero-junio). La problemática de los límites al poder de reforma de la Constitución Política de 1991. Revista Facultad de Derecho y Ciencias Políticas. (43), 118: 309-348. Recuperado de http://www.scielo.org.co/pdf/rfdcp/v43n118/v43n118a10.pdf.

Lasalle, F. (1994) ¿Qué es una Constitución? 4. ${ }^{a}$ Edición. Barcelona, España: Ariel S.A. Recuperado de https://norcolombia.ucoz.com/libros/Lassalle_Ferdinand-Que_Es_Una_Constitucion.pdf 
Zuluaga, R. (2008, julio-diciembre). ¿Supremacía o reforma? Una aproximación a la constitución con especial referencia a Colombia. Vniversitas, (116), 31-52. Recuperado de https://www.redalyc.org/ pdf/825/82515355002.pdf 